\title{
Study of the Effect of Grafted Antioxidant on the Acrylonitrile-Butadiene Copolymer Properties
}

\author{
Abdulaziz Ibrahim Al-Ghonamy ${ }^{1}$ and Mirham A. Barakat ${ }^{2,3}$ \\ ${ }^{1}$ Faculty of Engineering, Hail University, Hail, P.O. Box 2440, Saudi Arabia \\ ${ }^{2}$ Faculty of Science, Hail University, Hail, P.O. Box 2440, Saudi Arabia \\ ${ }^{3}$ National Institute of Standards, Tersa Street, El-Harm, P.O. Box 136, Giza 12211, Egypt \\ Correspondence should be addressed to Mirham A. Barakat, mirham75@yahoo.com \\ Received 12 September 2009; Revised 15 January 2010; Accepted 12 May 2010 \\ Academic Editor: Joseph L. Keddie
}

Copyright (C) 2010 A. I. Al-Ghonamy and M. A. Barakat. This is an open access article distributed under the Creative Commons Attribution License, which permits unrestricted use, distribution, and reproduction in any medium, provided the original work is properly cited.

The grafting of ADPEA onto natural rubber was executed with UV radiation. Benzoyl peroxide was used to initiate the freeradical grafting copolymerization. Natural rubber-graft- $N$-(4-aminodiphenylether) acrylamide (NR- $g$-ADPEA) was characterized with an IR technique. The paper aims interested to determine the crosslinking density by using the ultrasonic technique. The ultrasonic velocities of both longitudinal and shear waves were measured in thermoplastic discs of NBR vulcanizates as a function of aging time. Ultrasonic velocity measurements were taken at $2 \mathrm{MHz}$ ultrasonic frequency using the pulse echo method. We studied the effect of aging on the mechanical properties, crosslinking density, and the swelling and extraction phenomena for acrylonitrile-butadiene copolymer (NBR) vulcanizates, which contained the prepared NR-g-ADPEA and a commercial antioxidant, $N$-isopropyl- $N^{-}$-phenyl-p-phenylenediamine. The prepared antioxidant enhanced both the mechanical properties of the NBR vulcanizates and the permanence of the ingredients in these vulcanizates.

\section{Introduction}

Recently attempts have been made to study the ultrasonic velocity and attenuation of polymers. When propagated in polymeric materials, acoustic waves are influenced by the polymer's structure and by molecular relaxation processes. It is possible to estimate the viscoelastic properties of polymeric materials from the velocity and attenuation of longitudinal or shear waves. Furthermore, ultrasonic methods have been successfully used to monitor polymer processing, chemical reactions, film formation from aqueous polymer dispersions, glue processes, crosslinking density, and crystallization in polymers.

Many industrial polymer products are exposed to various types of degradation by the subjection of polymer products to heat, various kinds of radiation, and mechanical stresses. Main-chain scission takes place, so their mechanical properties worsen. These degradation processes are considerably accelerated in the presence of oxygen. Degradation processes of polymers are influenced by the addition of various kinds of stabilizers, which should lower the rate of degradation via reactions with various radicals formed by polymer mainchain scission, isomerization, and free-radical transfer, as indicated by an inhibition of the oxidative degradation.

The reaction of a peroxy radical with an inhibitor plays the main role in the retardation of polymer oxidation by antioxidants. The activity of antioxidants depends not only on their ability to trap peroxy and hydroperoxy radicals and the catalytic action in hydroperoxide decomposition but also on their compatibility with the polymer [1]. Antioxidants may be added to polymers to minimize the effects of oxidative degradation during processing at elevated temperatures or to prolong the service life of the finished product.

In the selection or design of antioxidants for practical situations, problems with the loss of antioxidants by both chemical and physical processes may be encountered. The chemical loss of an antioxidant can occur during processing if the base polymer is to be crosslinked; the antioxidant may be consumed by interfering with the crosslinking 


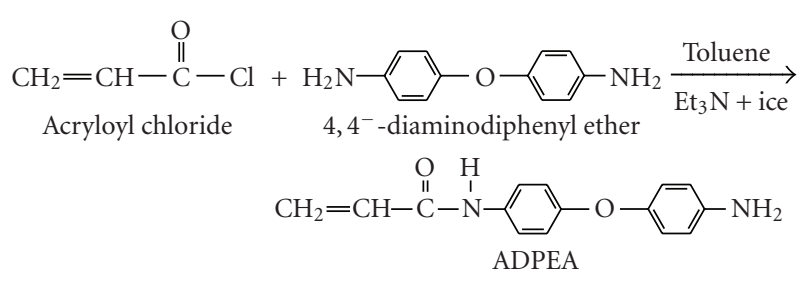

Scheme 1

reactions [2]. The net result is that the concentration of the antioxidant in the base polymer is reduced, and so the service life of the product is shortened. Physical losses of an antioxidant can occur during the processing of the polymer if the antioxidant is sufficiently volatile at the fabrication temperature. Antioxidants also may diffuse to the surface, or those that are soluble in molten polymers may become insoluble at service temperatures and may separate out preferentially on the surface. This phenomenon is known as blooming, and the subsequent loss of the antioxidant then occurs from the polymer surface by evaporation. Finally, if the polymer is in contact with appropriate solvents during service, these may lead to the loss of a soluble antioxidant via leaching [3]. To avoid the loss of antioxidants through extraction or volatilization; macromolecular, polymerizable, or grafting antioxidants may be used [4]. Highmolecularweight antioxidants and polymerizable antioxidants do not ensure the protection of the entire volume because they cannot diffuse through the rubber. Grafted antioxidants are high-molecular-weight compounds that bond by chemical treatments to the macromolecules or sometimes during the processing of the polymer, and the use of grafting antioxidants is one of the best ways of protecting unsaturated rubbers $[5,6]$.

Irradiating the polymer in the presence of a solvent containing a monomer leads to photo grafting. UV radiation is well absorbed by UV initiators, so a photoinitiator (e.g., benzoyl peroxide and its derivatives) is used to initiate the reaction [7]. UV irradiation appears to be an excellent method for grafting copolymerization because of its simplicity and cleanliness and the lower cost of its energy source.

\section{Experimental}

2.1. Materials. $4,4^{-}$-Diaminodiphenyl ether and benzoyl peroxide were supplied by Fluka Chemie AG (Postfach 260, CH-9471 Buchs, Switzerland) and Sigma-Aldrich Co. (Milwaukee, WI), respectively. Acryloyl chloride and triethylamine were obtained from Merck (Sarmstadt, Germany). All solvents were laboratory-grade and were supplied by Edwic (Cairo, Egypt).

2.2. Synthesis of N-(4-Aminodiphenyl Ether) Acrylamide (ADPEA). 4,4--Diaminodiphenyl methane $(0.1 \mathrm{~mol})$ in $100 \mathrm{~mL}$ of toluene was stirred with $0.1 \mathrm{~mol}$ of Et $3 \mathrm{~N}$ in an ice bath. Acryloyl chloride ( 0.1 mole) was added dropwise. After the addition, the reaction mixture was stirred for $2 \mathrm{~h}$, left overnight, and then filtered [8]. The filtrate was dried, and
TABle 1: Degree of grafting of NR- $g$-ADPEA.

\begin{tabular}{lc}
\hline Prepared grafted antioxidant & Degree of grafting (\%) \\
\hline NR-graft-ADPEA & 27.00 \\
\hline
\end{tabular}

the product, obtained as a solid, was then crystallized from tetrahydrofuran/heptane mixtures. The synthesis of ADPEA is graphically presented in Scheme 1.

\subsection{Synthesis of Natural Rubber-Graft-N-(4-Aminodiphenyl} Ether) Acrylamide (NR-g-ADPEA). UV irradiation was performed with a low-pressure mercury lamp. The power supply model was SCT- 1A/F (230 V, $0.15 \mathrm{~A}, 50 \mathrm{~Hz})$. The UV pencil lamp model was 11 SC-LOP (short-wave UV, $254 \mathrm{~nm}$ ) (Westbury, NY).

Natural rubber (NR; 1,4-polyisoprene; $3 \mathrm{~g}$ ) was dissolved in $300 \mathrm{~mL}$ of toluene, with constant stirring, at room temperature in a reaction bottle. The NR solution was irradiated for $24 \mathrm{~h}$ by a UV lamp. Mohr's salt (ferrous ammonium sulfate; $0.0588 \mathrm{~g}$ ), $0.6 \mathrm{~g}$ of ADPEA, and $0.0015 \mathrm{~g}$ of benzoyl peroxide were added to the contents of the reaction bottle. The reaction was allowed to proceed for $14 \mathrm{~h}$. After that, the reaction mixture was poured into ethanol to precipitate ungrafted NR. The grafted NR was isolated by the evaporation of the solution. The grafting percentage was taken as the ratio of the graft yield to NR multiplied by 100 [9]:

$$
\text { Degree of grafting }=W_{g} / W_{\mathrm{NR}} * 100,
$$

where $W_{\mathrm{NR}}$ is the weight of NR and $W_{g}$ is the weight of the graft yield. The degree of grafting was calculated and is reported in Table 1.

The synthesis of NR-g-ADPEA is graphically presented in Scheme 2.

2.4. Characterization of ADPEA and NR-g-ADPEA. IR spectroscopy data were recorded on a PerkinElmer 11650 FTIR spectrometer (Wellesley, MA) to elucidate the structure and to ensure the purity of the products. The IR spectroscopy data for ADPEA and NR- $g$-ADPEA are summarized in Tables 2 and 3.

Figures 1, 2, and 3 present the IR spectra of ADPEA, NR, and NR- $g$-ADPEA, respectively. The IR spectrum of NR is shown in Figure 3. The spectrum shows the characteristic peaks of the $-\mathrm{C}=\mathrm{C}-$ group at $1693.4 \mathrm{~cm}^{-1}$, the $-\mathrm{CH}_{2}-\mathrm{C}(\mathrm{CH} 3) \mathrm{H}-$ group at $2693.4 \mathrm{~cm}^{-1}$, and the $-\mathrm{CH}_{2}$ group at $1423.5 \mathrm{~cm}^{-1}[9]$. 


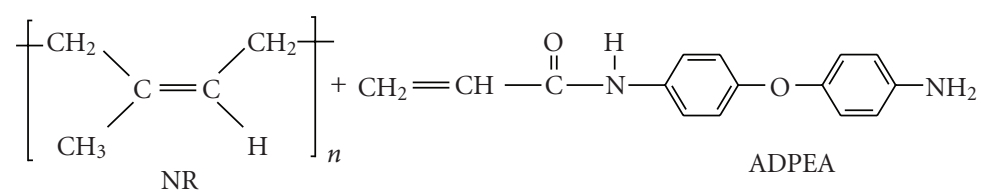

UV $\downarrow$ Benzoyl peroxide

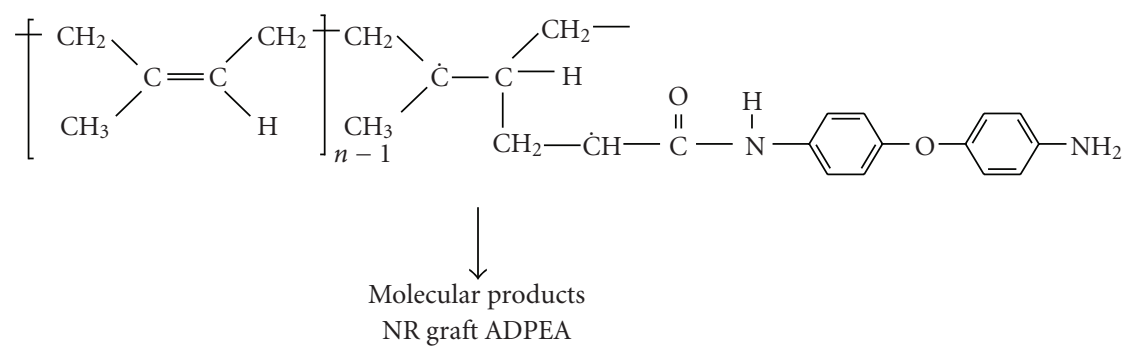

SCHEMe 2

TABLE 2: Spectral properties of ADPEA.

\begin{tabular}{lc}
\hline Name & IR \\
\hline & $-\mathrm{CH}_{2}=\mathrm{CH}-, 1060.0$ \\
ADPEA & Amide I, 1613.1 \\
& Amide II, 1500.6 \\
& $\mathrm{NH}, 3275.5$ \\
& $\mathrm{NH}_{2}, 1424.3$ \\
\hline
\end{tabular}

TABLE 3: Spectral properties of NR-g-ADPEA.

\begin{tabular}{lc}
\hline Name & IR \\
\hline & Amide I, 1599.4 \\
NR- $g$-ADPEA & Amide II, 1577.9 \\
& $\mathrm{NH}, 2959.0$ \\
& $\mathrm{NH}_{2}, 1277.2$ \\
\hline
\end{tabular}

The IR spectra of Figures 1-3 were compared. In the spectrum of Figure 3, the intensity of the double-bond absorption peak for NR and ADPEA decreases, and a new absorption appears for $\mathrm{NH}, \mathrm{NH} 2$, and amide groups. The results prove that ADPEA was grafted onto NR.

2.5. Crosslinking Density Measurement. The crosslinking density of the NBR vulcanizates, which contain PBN, NRgraft-ADPEA, and control mix were measured by using untrasonic technique, pulse echo technique. The ultrasound measurements in this study were performed using the following equipments: oscilloscope (54615B $h p$, USA) had been used to obtain the time traveling through specimen flaw detector (USIP 20 Krautkramer, Germany) had been used to display echo step block, VI and VII blocks had been used as reference steel blocks (having known thickness and

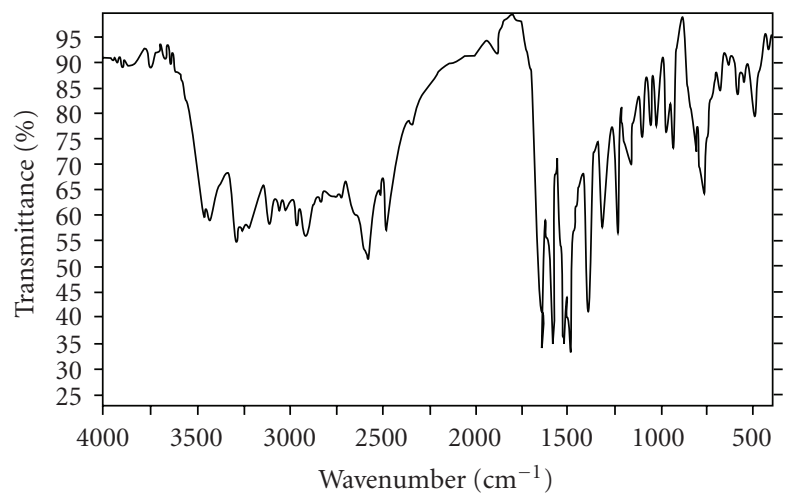

FIGURE 1: IR spectrum of ADPEA.

velocity), and Transducer (Krautkramer, Germany) having $2 \mathrm{MHz}$ frequency [10]

$$
\begin{array}{ll}
\mu=0.93 C_{T}^{2} & \mu \text { and } \lambda \text { are Lame' constants, } \\
\lambda=0.93\left(\left(C_{L}^{2}\right)-2\left(C_{T}^{2}\right)\right) & C_{L} \text { is the longitudinal velocity, } \\
C_{T} \text { is the shear velocity, } \\
\sigma=\frac{\lambda}{2}(\lambda+\mu) & \sigma=\text { Poisson's ratio, } \\
n_{c}=\frac{\sigma^{1 / 4}}{0.28} & n_{c}=\text { crosslink density. }
\end{array}
$$

2.6. Mixing and Processing. The mixes examined in this study were based on an acrylonitrile-butadiene copolymer (NBR) with the trade name Humex N-34/47, which is produced by Polymer Corporation (Cosne sur Loire, France). NBR mix formulations containing IPPD, NR-g-ADPEA, and control mix are given in Table 4. 


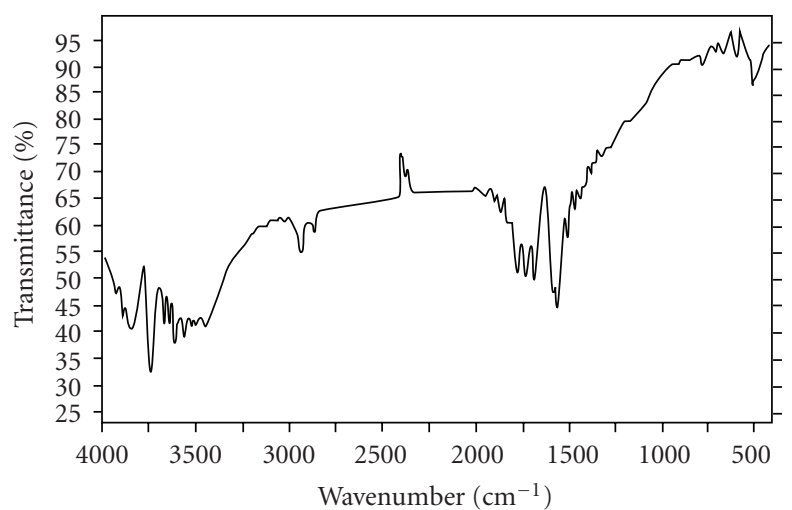

FIGURE 2: IR spectrum of NR.

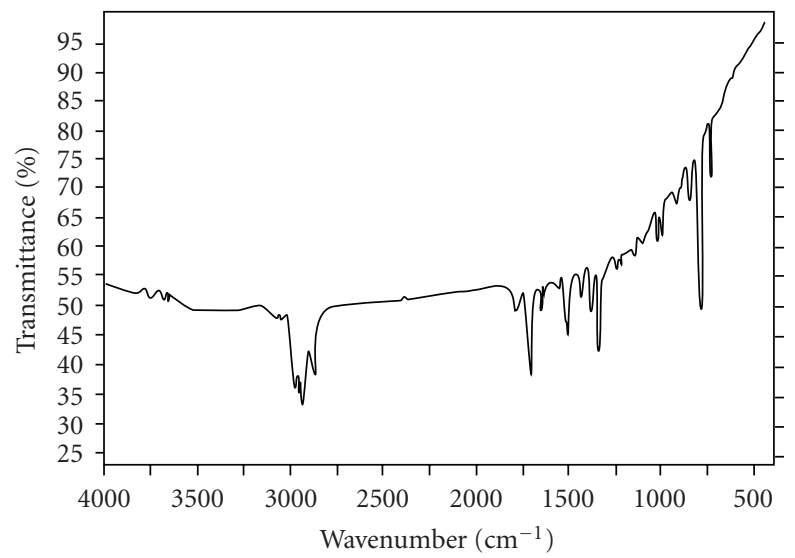

FIGURE 3: IR spectrum of NR-graft-ADPEA.

A semireinforcing furnace (SRF) was used as a carbon black filler in the NBR mixes, and the main properties of the SRF are given in Table 5.

Zinc oxide as an inorganic accelerator activator and stearic acid as an organic acid accelerator activator were used to activate the accelerators used in the vulcanization process. The accelerators were mercaptobenzothiazole (MBT) and tetramethyl thiuram disulfide (TMTD). Elemental rhombic sulfur was used as a vulcanizing agent in all mixes. All rubber mixes were prepared on a water-cooled, two-roll mill $150 \mathrm{~mm}$ in diameter and $300 \mathrm{~mm}$ wide. The roll temperature was kept at about $50^{\circ} \mathrm{C}$ during mixing. The rubber mixes were vulcanized at $152^{\circ} \mathrm{C}$ with an electric press for the optimum cure time, which was indicated by a Monsanto rheometer (Swindon, UK). A vulcanized sheet $20 \mathrm{~cm}$ long and $2 \mathrm{~mm}$ thick was obtained. Test pieces were cut from this sheet for the determination of the different properties of the prepared rubber mixes.

\section{Results and Discussion}

The prepared NR-g-ADPEA was incorporated into an NBR vulcanizate, and we used a mechanical technique and swelling and extraction phenomena to study the effect of
TABLE 4: NBR Mix Formulations Containing, IPPD, NR- $g$-ADPEA, and control mix.

\begin{tabular}{lccc}
\hline Mix ingredient (phr) & \multicolumn{3}{c}{ Sample } \\
& A1 & A2 & A3 \\
\hline NBR & 100 & 100 & 100 \\
ZnO & 5 & 5 & 5 \\
Stearic acid & 2 & 2 & 2 \\
Processing oil & 5 & 5 & 5 \\
SRF & 30 & 30 & 30 \\
Sulfur & 1.5 & 1.5 & 1.5 \\
MBT & 0.75 & 0.75 & 0.75 \\
TMTD & 0.75 & 0.75 & 0.75 \\
IPPD & - & 1 & - \\
NR-g-ADPEA & - & - & 4 \\
Cure time, min & 8.7 & 5.3 & 9.96 \\
Scorch time, min & 2.48 & 1.96 & 1.23 \\
\hline
\end{tabular}

TABLE 5: Main properties of SRF.

\begin{tabular}{lcc}
\hline Name & Particle size $\left(\mathrm{A}^{\circ}\right)$ & $\mathrm{pH}$ \\
\hline SRF & 800 & 9.9 \\
\hline
\end{tabular}

the prepared antioxidant on the NBR vulcanizate properties. Because $N$-isopropyl- $N_{-}$-phenyl- $p$-phenylenediamine (IPPD) is still the most widely used antioxidant for rubber, we used it to judge the ability of the prepared antioxidant to protect NBR vulcanizates.

3.1. Effect of Aging on the Mechanical Properties of the NBR Vulcanizates. NBR mixes were vulcanized at $152^{\circ} \mathrm{C}$ with an electric press for the cure time. Unaged, dumbbell shaped samples were prepared, and their tensile strength, and elongation at break were measured with a Zwick model Z010 tensile testing machine (Ulm, Germany). NBR vulcanizates were aged in an oven fixed at $90^{\circ} \mathrm{C}$ for $2,4,6$, and 7 days.

Figures 4, 5, and 6 illustrate the relations between the retained values of the mechanical properties and the aging time. In each figure, curves representing the investigated antioxidant, IPPD, and a control mix are presented. Figure 4 shows the relationship between the retained values of the tensile strength and aging time; the NBR vulcanizate containing the prepared antioxidant had higher tensile strength than the mix containing IPPD and the control mix.

Figure 4 indicates that the tensile strength of the NBR mixes containing the commercial antioxidant and the prepared antioxidant increased with increasing aging time up to 4 days, and then decreased with increasing aging time because generally aging causes crosslinking and crosslink cleavage in NBR vulcanizates. When aging was initiated, the rate of crosslink formation was more than that of crosslink cleavage [11]. With increasing aging time, the rate of crosslink cleavage increased gradually as shown in Figure 5.

The relation between the crosslinking density of NBR vulcanizates, which contain PBN, Nr-graft-ADPEA, and control mix, and the aging time are shown in Figure 5. 


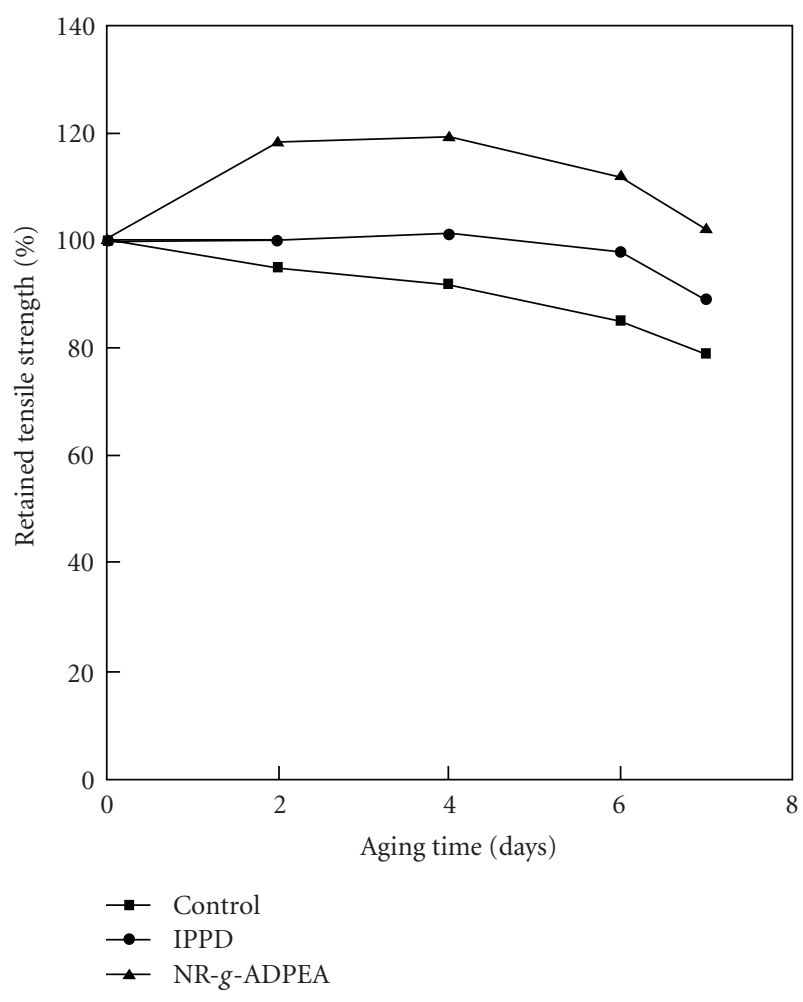

Figure 4: Relation between retained tensile strength, \% and aging time, days for NBR vulcanizates, which contain IPPD, and NRgraft-ADPEA and control vulcanizate.

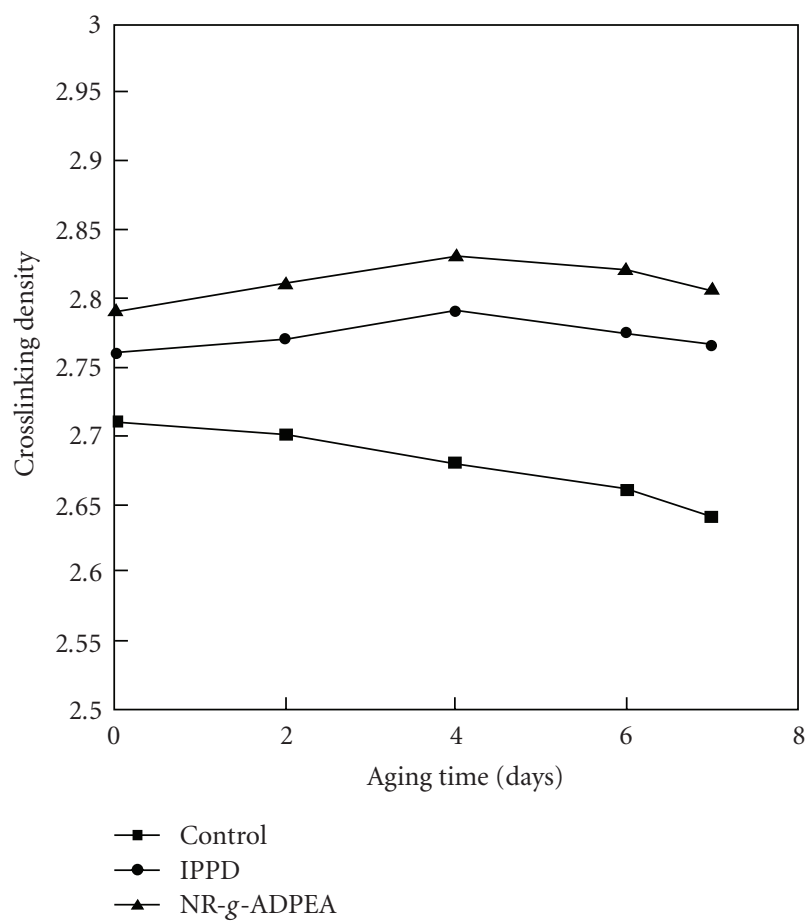

FIGURE 5: Relation between the crosslinking density and aging time for an NBR control mix and NBR mixes containing IPPD and NR$g$-ADPEA.

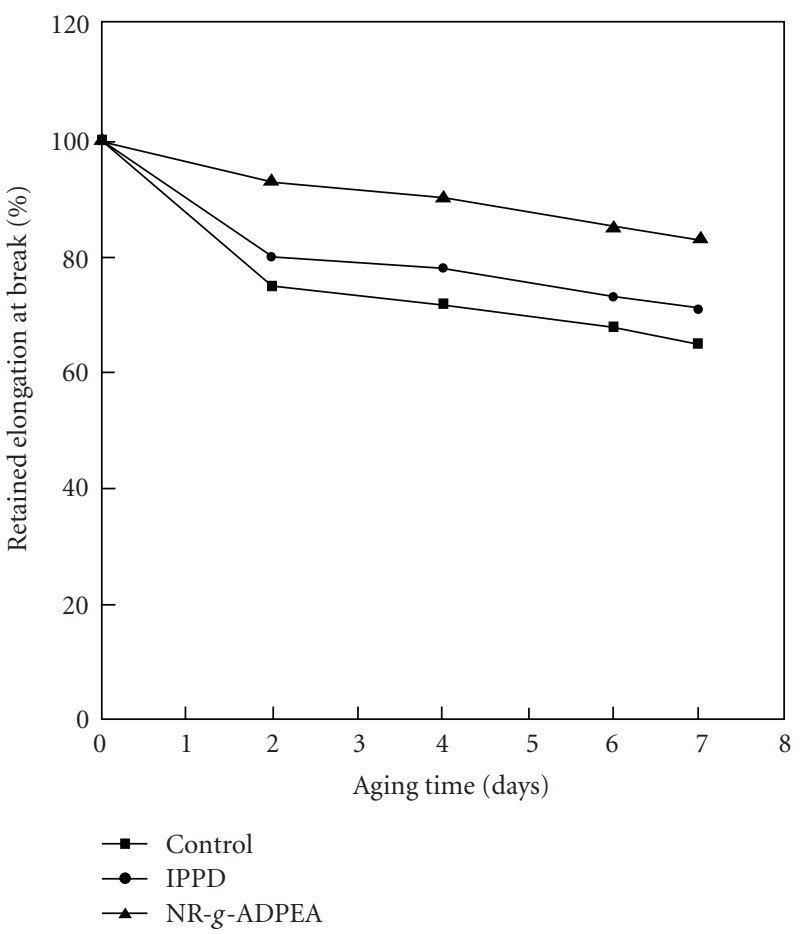

FIGURE 6: Relation between retained elongation at break, \% and aging time, days for NBR vulcanizates which contain IPPD, and NRgraft-ADPEA and control vulcanizate.

From Figure 5 it can be noted that the crosslinking density within the NBR vulcanizates, which contain PBN and the prepared NR-graft-ADPEA increased with increasing aging time 4 days then decreased with increasing aging time up to 7 days. Because up to 4 days aging time, the vulcanization process was completed then the aging caused the degradation for the crosslink between NBR vulcanizates with increased aging time from 4 days up to 7 days [9].

Figure 6 shows that the mix containing the prepared NR-g-ADPEA compound had high-retained values of the elongation at break in comparison with the mix containing the commercial antioxidant and the control mix. Finally, we can say that NR-g-ADPEA provided significant protection to NBR vulcanizates in comparison with the mix containing the commercial antioxidant and the control mix. This can be attributed to the following.

(1) The ease of liberating the active hydrogen atom from the para position to deactivate peroxy radicals formed by aging $[11,12]$.

(2) The resonance stability of the resulting grafted antioxidant radical, which minimized the possibility of chain-transfer reactions is responsible for further rubber degradation by aging $[12,13]$.

(3) The grafted antioxidants, which were high molecular antioxidants that partially bonded to the macromolecules during the processing of the polymers and had a good ability to diffuse through the unsaturated rubber [5]. 


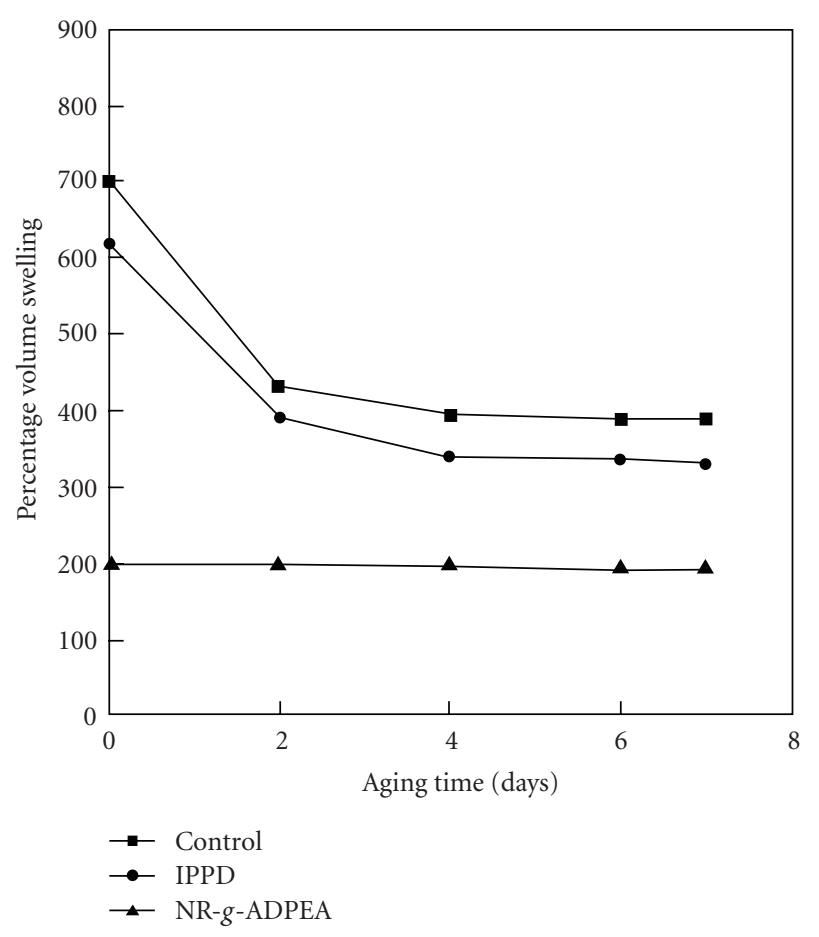

FIGURE 7: Relation between the volume swelling and aging time (days) for an NBR control mix and NBR mixes containing IPPD and NR- $g$-ADPEA.

3.2. Effect of Aging On the Volume Swelling Percentage and Volume Extraction Percentage of the NBR Vulcanizates in Toluene. The swelling of rubbers by solvents is an important aspect to be considered, especially for sealing applications [12]. When a certain rubber is in contact with a solvent, a swelling process happens. If the number of crosslinks increases, the distance between crosslinks shortens, and consequently swelling is reduced and vice versa. The properties of industrial polymer products depend on the volume swelling percentage and the volume extraction percentage. When the volume extraction percentage of polymer products decreases, polymer products retain the incorporated ingredient. Here we report the effect of the prepared NR- $g$ ADPEA on the values of the volume swelling percentage and volume extraction percentage for aged samples. To achieve this, the samples were immersed in toluene until maximum swelling was reached. The effect of aging on the swelling behavior of the investigated samples containing the prepared antioxidant, IPPD, and the control mix is illustrated in Figure 7. All the samples possessed higher volume swelling percentage values before aging. These values markedly decreased after 2 days of aging and further decreased as the aging continued up to 7 days. Such a phenomenon could be attributed to the hindrance of the solvent uptake brought about by the additional crosslinks that were formed with the exposure of the rubber samples to aging [11]. The prepared antioxidant showed lower swelling values than the mix containing the commercial antioxidant and the control mix.

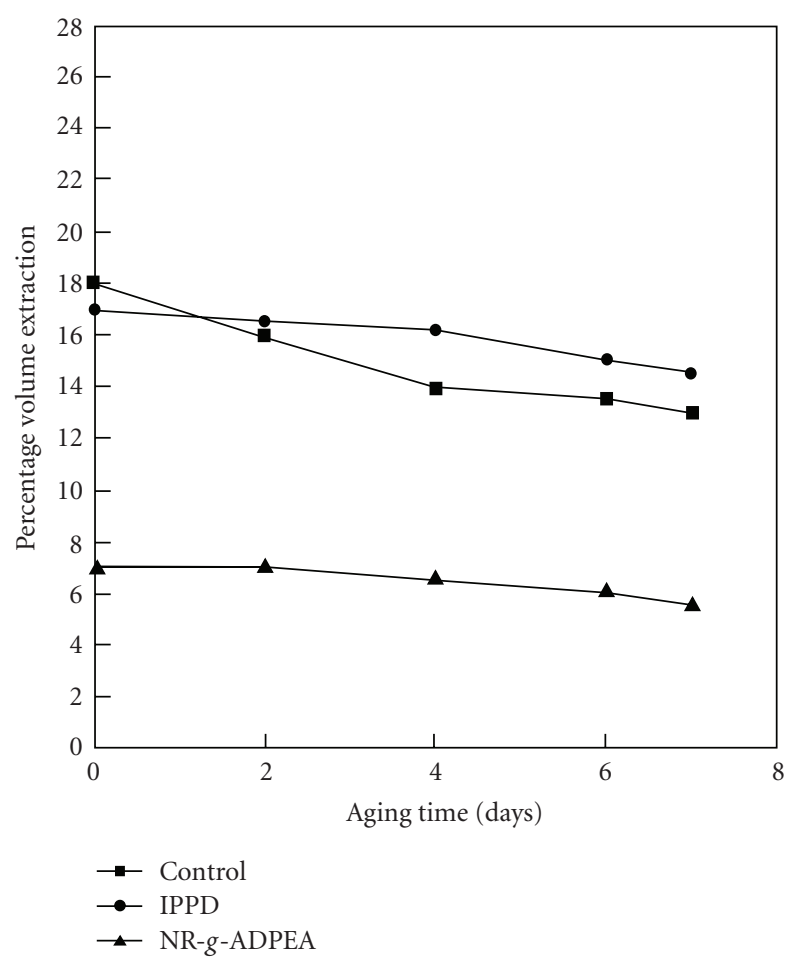

FIgURE 8: Relation between the volume extraction and aging time (days) for an NBR control mix and NBR mixes containing IPPD and NR-g-ADPEA.

The volume extraction percentage of the swelled samples was calculated and plotted against the aging time, as shown in Figure 8.

The results clearly indicate that the antioxidant NR-gADPEA significantly lowered the percentage of extractable ingredients with the aging time in comparison with the control mix and the mix containing the commercial antioxidant. This means that the grafted antioxidant was a high molecular antioxidant that partially bonded to the macromolecules during the processing of the polymers and hindered the reaction of the swelling solvent with the ingredients inside the rubber matrix. The results obtained for the volume swelling percentage and volume extraction percentage constitute very significant evidence for the NR-g-ADPEA antioxidant being of great value for rubber industry applications.

\section{Conclusions}

UV irradiation is an excellent approach for grafting ADPEA onto NR. NR-g-ADPEA provided significant protection to NBR vulcanizates in comparison with a mix containing a commercial antioxidant (IPPD) and a control mix because the grafted antioxidants were high molecular antioxidants that partially bonded to the macromolecules during the processing of the polymers.

The ultrasonic technique is the best technique to determine the crosslinking density without causing any deformation of polymeric products. The results obtained for the volume swelling percentage and volume extraction 
percentage constitute very significant evidence for the NR-gADPEA antioxidant being of great value for rubber industry applications. Therefore, NR-g-ADPEA could improve the economic value of polymer products.

\section{References}

[1] F. Hrabac and A. Posta, Czech. Pat. CS249,095 (1988); Chemical Abstracts 1989, vol. 11, p. 39517.

[2] V. Haddadi-Asl, R. P. Burford, and J. L. Garnett, "Radiation graft modification of ethylene-propylene rubber-II. Effect of additives," Radiation Physics and Chemistry, vol. 45, no. 2, pp. 191-198, 1995.

[3] S. Al-Malaika, A. Q. Ibrahim, M. J. Rao, and G. Scott, "Mechanisms of antioxidant action. photoantioxidant activity of polymer-bound hindered amines. II. Bis acrylates," Journal of Applied Polymer Science, vol. 44, no. 7, pp. 1287-1296, 1992.

[4] J. M. Herdan and M. Giurginca, "Grafting antioxidants. V Phenols with mercaptoheterocyclic substituents as antioxidants for dienic rubbers," Polymer Degradation and Stability, vol. 41, no. 2, pp. 157-162, 1993.

[5] M. Giurginca, J. M. Herdan, L. Cira, G. Văleanu, and G. Ivan, "Grafted mercapto-1,3,5-triazinic antioxidants for elastomers," Polymer Degradation and Stability, vol. 36, no. 1, pp. 53-57, 1992.

[6] P. Flory, "Effects of molecular structure on physical properties of butyl rubber," Journal of Industrial and Engineering Chemistry, vol. 38, no. 4, pp. 417-436, 1946.

[7] J. J. Yu and S. H. Ryu, "Ultraviolet-initiated photografting of glycidyl methacrylate onto styrene-butadiene rubber," Journal of Applied Polymer Science, vol. 73, no. 9, pp. 1733-1739, 1999.

[8] A. B. Shehata, S. N. Lawandy, and A. A. El-Wakeel, "Acrylonitrile-butadiene rubber stabilized by methacrylamides as antioxidants," Polymer-Plastics Technology and Engineering, vol. 39, no. 1, pp. 1-21, 2000.

[9] S. A. Avirah and R. Joseph, "Studies on natural rubber bound para-phenylenediamine antioxidants in NBR," Journal of Applied Polymer Science, vol. 57, no. 12, pp. 1511-1524, 1995.

[10] H. Afifi and A. A. El-Wakil, "Study of the effect of natural rubber-graft-maleic anhydride (NR-g-MA) on the compatibility of NR-NBR blends using the ultrasonic technique," Polymer-Plastics Technology and Engineering, vol. 47, no. 10, pp. 1032-1039, 2008.

[11] N. M. Claramma, N. M. Mathew, and E. V. Thomas, "Radiation induced graft copolymerization of acrylonitrile on natural rubber," Radiation Physics and Chemistry, vol. 33, no. 2, pp. 87-89, 1989.

[12] S. N. Lawandy, A. F. Younan, and A. B. Shehata, "Acrylamides as amino antioxidants for acrylonitrile-butadiene rubber compounds," Polymer-Plastics Technology and Engineering, vol. 35, no. 2, pp. 207-220, 1996.

[13] S. N. Lawandy, A. F. Younan, and A. B. Shehata, "Acrylamides as phenolic antioxidants for acrylonitrile-butadiene rubber compounds," KGK-Kautschuk und Gummi Kunststoffe, vol. 50, no. 6, pp. 452-455, 1997. 

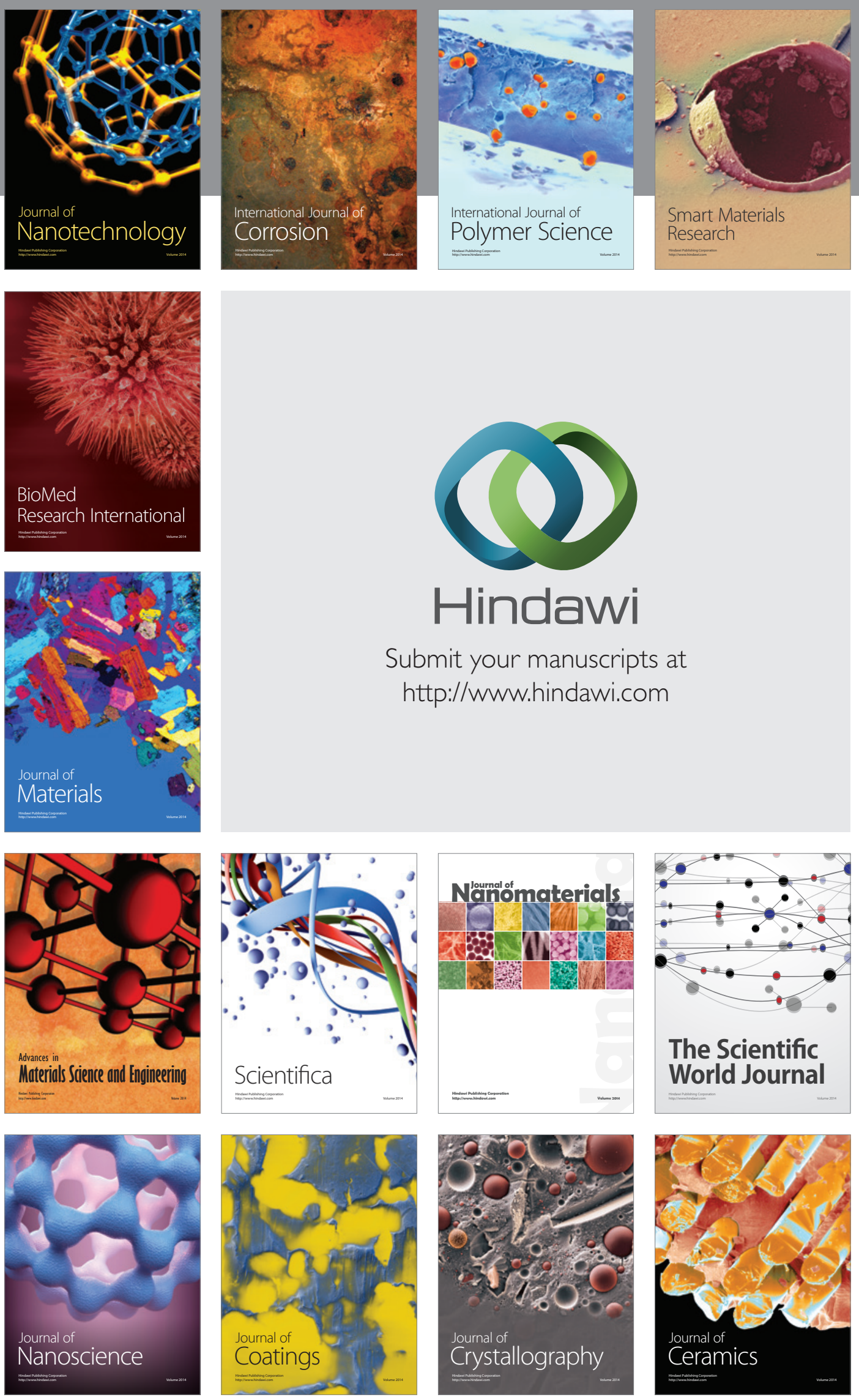

The Scientific World Journal

Submit your manuscripts at

http://www.hindawi.com

\section{World Journal}

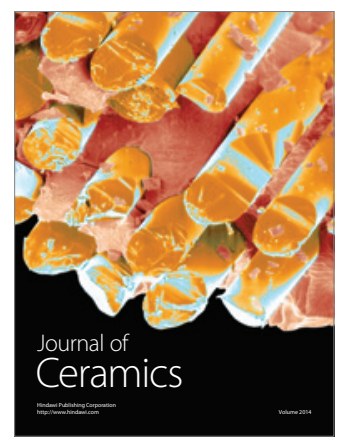

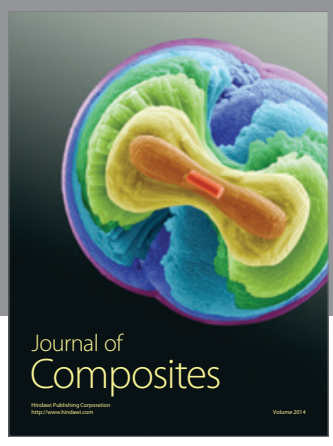
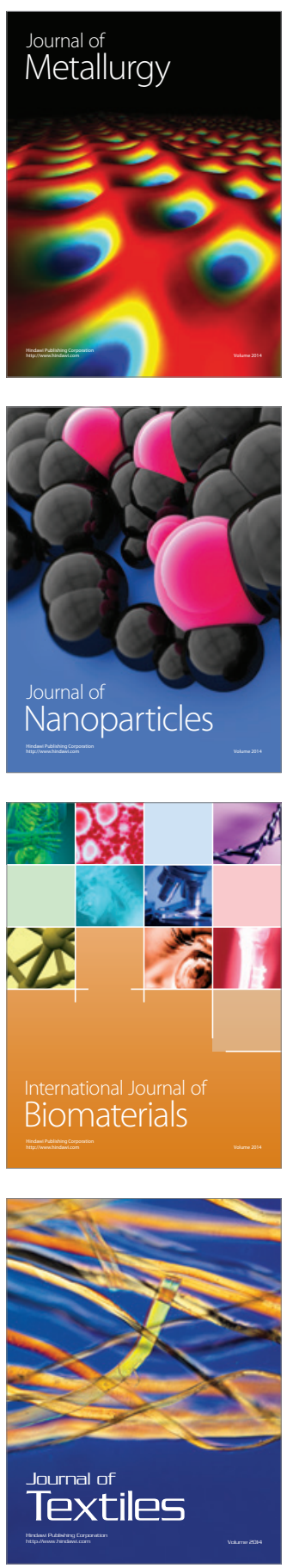